\title{
Outline and Issues of Internet Addiction
}

\author{
Kazuto Doi ${ }^{1,2}$, Mayumi Doi ${ }^{3}$, Yukoh Yaegashi ${ }^{4}$ and Mitsuhiro Nishitani*5 \\ ${ }^{1}$ Department of Pathophysiology, Faculty of Medicine, Oita University, Japan \\ ${ }^{2}$ Department of Medical Engineering, Faculty of Allied Health Sciences, University of East Asia, Japan \\ ${ }^{3}$ Department of Clinical Pharmacology \& Therapeutics, Faculty of Medicine, Oita University, Japan \\ ${ }^{4}$ Department of Medical Engineering, Faculty of Health Sciences, Junshin Gakuen University, Japan \\ ${ }^{5}$ Daimon Clinic for Internal Medicine, Nephrology and Dialysis, Japan
}

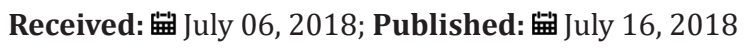

*Corresponding author: Mitsuhiro Nishitani, Daimon Clinic for Internal Medicine, Nephrology and Dialysis, Ishikawa 921-8802, Japan

\section{Introduction}

The Internet has been spreading rapidly since the late 1990's. It exists as an indispensable tool in contemporary society. Japan's individual Internet users have reached $80 \%$ of the population, which is convenient, but on the other hand, it is internet addiction that is becoming a some of problem. This review addresses the problems caused by Internet addiction.

\section{What is Internet Addiction}

The term "Internet addiction" refers to a situation in which "control over the use of the Internet becomes difficult and, despite various problems, it is in a state where it cannot be stopped". It proposed first by Ivan Goldberg in 1995 [1]. Although there is no definite diagnostic criteria of Internet addiction, Internet game disorder is indicated as an item under study in the Diagnostic and Statistical Manual of Mental Disorders (DSM) published by American Psychiatric Association (Table 1). The first edition of DSM was published in 1952 and has been revised several times since then, DSM-5 was released in May 2013 [2]. DSM was created mainly by psychiatrists for the aptitude assessment of soldiers during the Second World War and the treatment diagnosis of returned soldiers. It is effectively used as an international diagnostic manual. When introducing some of the items of Internet game disorder shown in DSM-5, withdrawal symptoms occur when taking Internet games, despite recognizing tolerance and social problems, continue excessive use of Internet games, and so on. Internet game disorders are characterized by many social problems such as poor academic achievement, school refusal, social withdrawal, sleep disorder and depression.

Table 1: DSM-5 IGD-Internet gaming disorder.

\begin{tabular}{|c|c|}
\hline \multicolumn{2}{|r|}{ DSM-5 IGD-Internet Gaming Disorder } \\
\hline 1 & $\begin{array}{l}\text { Pre occupation with games: the individual thinks about previous gaming activity or anticipates playing the } \\
\text { next game; gaming becomes the dominant activity in daily life }\end{array}$ \\
\hline 2 & $\begin{array}{l}\text { With drawl symptoms when gaming is taken away: these symptoms are typically described as irritability, } \\
\text { anxiety, or sadness }\end{array}$ \\
\hline 3 & Tolerance: the need to spend increasing amounts of time engaged in games \\
\hline 4 & Unsuccessful attempts to control or reduce participation in games \\
\hline 5 & $\begin{array}{c}\text { Loss of Interest in real life relationships, previous hobbies, and other entertainment as a result of, and with } \\
\text { the exception of, games }\end{array}$ \\
\hline 6 & Continued excussive use of games despite knowledge of psychological problems \\
\hline 7 & Has decided family members, therapists, or other regarding the amount of gaming \\
\hline 8 & Use of games to escape or relieve a negative mood (eg, feelings of helplessness, guilt, or anxiety) \\
\hline 9 & $\begin{array}{l}\text { Has jeopardized or last a significant relationships, job, or educational career opportunity because of } \\
\text { participation in games. }\end{array}$ \\
\hline
\end{tabular}

\section{State of Internet Addiction on Each Country}

The Internet began to spread in the latter half of the 1990s, its history is still shallow. However, in the United States, it has been reported about Internet addiction in 1998. In 2003, also in Korea, Internet subscribers to the population of one million people became the number one in the world and the number of young people immersed in online games has increased rapidly. According to Korea's statistics in $2009,12.8 \%$ of young people and $6.4 \%$ of adults were reported to be Internet addiction [3]. In the Norwegian survey, it was reported that males were more likely to depend on the Internet at the ages of 16 to 29 [4], and survey in China, middle to high school and university students aged 10 to 24 , men 
showed $10.4 \%$, women reported $5.9 \%$ respectively [5]. Although the Internet addiction tends to be relatively large in the young generation, since there are large variations, it is only necessary to have a unified manual for diagnosing the Internet addiction, but it seems that there is no such a manual.

\section{Subject of Internet Addiction}

DSM-5, which is a de facto international manual, is often used as a diagnostic criterion for Internet addiction, but it is not made by referring to Internet addiction. Internet addiction patients do not mean those who do nothing but online games. Those who are continuing to watch videos, those who are surfing the Internet, those who are building human relationships via SNS etc., and those who use gambling or pornographic sites. There are such various types of Internet addiction patients, but classically they are classified into five types by Young et al. That is,
a) Cybersexual addiction,
b) Cyber-relational addiction,
c) net compulsions,
d) Information overload,
e) Computer addiction [6].

However, the advancement of the Internet technology is fast, there is a possibility that a new type of Internet addiction patient will appear in the future. Since it seems that some parts cannot be dealt with by classical classification, we are forced to negotiate the urgent need to formulate guidelines specialized for Internet addiction.

\section{Secondary Problem of Internet Addiction}

Although Internet addiction often matches other dependencies such as health problems, monetary economic problems, mental problems such as human relations, it contains essentially different problems. In the case of online game dependence as an example, since Internet use from midnight to dawn is the most frequent, sleep disturbance is caused almost certainly due to insufficient sleep. The most problematic thing in this sleep disorder is depression. In the case of a student, problems such as poor academic achievement, late arrival, absence, failure to go to school and other problems arise and even in subsequent life, it will have a great impact. In addition, from a viewpoint of dependence in a broad sense, it is reported that neurocyte damage in the human brain, such as alcoholism, can be seen in Internet dependent patients $[7,8]$.

\section{Conclusion}

In modern society, the Internet is an indispensable tool to our daily lives, and new services will be born through the Internet for the development of the technology in the future. However, because it is a convenient tool, there is a tendency to immerse people too much and depend heavily on it. Sleep disorder is inevitable in the Internet addiction, and the economic loss caused by sleep disorder is said to be 5 trillion yen [9]. It is urgently desirable to define and diagnose Internet addiction and formulate guidelines for treatment.

\section{References}

1. Mitchell P (2000) Internet addiction: genuine diagnosis or not? Lancet 355(9204): 632.

2. (2013) Diagnostic and Statistical Manual of Mental Disorder, ( $5^{\text {th }}$ Edn.), DSM-5. American Psychiatric Association, Washington DC, USA.

3. (2010) Korea National Information Society Agency: 2010 Informatization White Paper.

4. Bakken IJ, Wenzel HG, Götestam KG, Johansson A, Oren A (2009) Internet addiction among Norwegian adults: a stratified probability sample study. Scand J Psychol 50(2): 121-127.

5. Cao H, Sun Y, Wan Y, Hao J, Tao F (2011) Problematic Internet use in Chinese adolescents and its relation to phychosomatic symptoms and life satisfaction. BMC Public Health 14(11): 802.

6. Young K, Pistner M, O'Mara J, Buchanan J (1999) Cyber disorders: the mental health concern for the new millenium. Cyberpsychol Behav 2(5): 475-479.

7. Yuan K, Qin W, Wang G (2011) Microstructure abnormalities in adolescents with internet disorder. PLoS One 6(6): e20708.

8. Zhou Y, Lin FC, Du YS (2011) Gray matter abnormalities in internet addiction: a voxel-based morphometry study. Eur J Radiol 79(1): 92-95.

9. (1993) National Commission on Sleep Disorders Research (US). Wake up America: a national sleep alert: report of the National Commission on Sleep Disorders Research.
ISSN: 2574-1241

DOI: 10.26717/BJSTR.2018.06.001415

Mitsuhiro Nishitani. Biomed J Sci \& Tech Res

This work is licensed under Creative Commons Attribution 4.0 License

Submission Link: https://biomedres.us/submit-manuscript.php

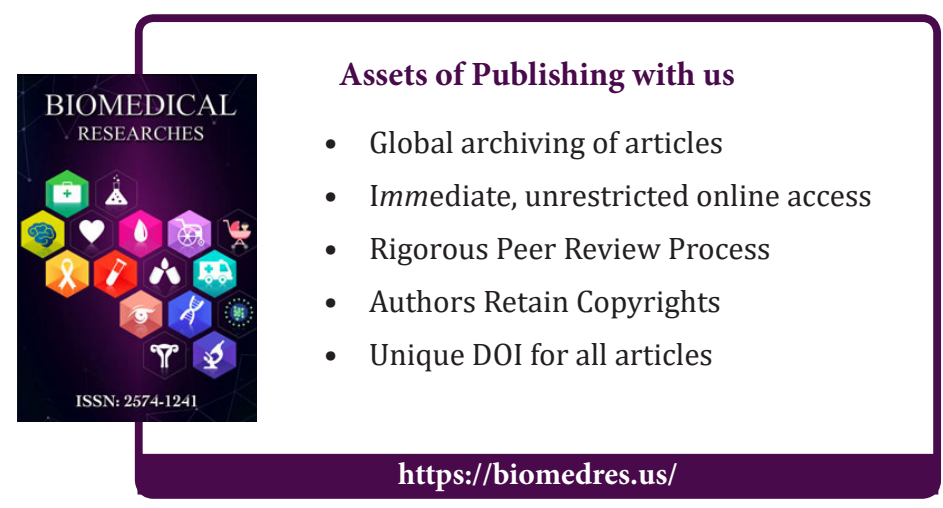

